in 2003. Entrepreneurs and scientists were already working on technologies to replace Sanger sequencing, the workhorse of the genome project. But these entrepreneurs and other genome technologists give at least some of the credit for the precipitous price drop to the NHGRI. In 2003 it launched the \$230-million Advanced Sequencing Technology programme, to support research to improve genome technology in academia and industry (see page 294). The programme will give out its final grants this year, but it has provided some key lessons on how to set up similar sponsored innovation efforts.

Set a clear goal. The NHGRI programme - often referred to as the $\$ 1,000$ genome programme - shares this feature with other successful technological endeavours, including the British government's eighteenth-century Longitude Prize for a practical method to determine a ship's position; NASA's Apollo Moon shot in the 1960s; and even the US Defense Advanced Research Projects Agency's contest to sponsor the creation of self-driving cars, first held in 2004. Stating a tangible goal galvanizes the field, harnessing researchers' collective brainpower to achieve a common aim.

Set the bar high, but not too high. The Archon Genomics X Prize was cancelled last year after only two teams signed up to take on its challenge: the sequencing of 100 complete human genomes in 30 days at unparalleled accuracy and low cost. That test was widely seen as too difficult, dissuading researchers from trying. The NHGRI, by contrast, seems to have set a more reasonable goal; before setting $\$ 1,000$ as its benchmark, it undertook a broad consultation of scientists in the field.

Spur competition. The 97 groups awarded grants by the NHGRI programme so far are made up of academics and companies working on a diverse range of concepts. Recipients have included a who's who of the sequencing industry past and present, as well as a huge array of people working on speculative ideas. Each grant - ranging from hundreds of thousands of dollars to a few million - is small compared with the amount of funding needed to take an idea all the way to market. But the spreading of money between so many competitors keeps the field lively, and keeps market leaders on their toes.

Foster cooperation. The programme convenes all grant recipients every year for a meeting, where all - including those from industry - are expected to describe their progress. Jeffery Schloss, the amiable head of the programme, deserves much of the credit for coaxing grant recipients to share information, and for promoting an atmosphere of
"Cheaper sequencing is changing science and beginning to change medicine." collegiality that has moved the field forward.

Seed a broad range of ideas. The vast majority of the programme's grants $75 \%$ so far - have gone to academics rather than companies. This has nurtured ideas that are too speculative for industry, ensuring that when the market weeds out less successful companies or throws up a monopoly, there is a nursery of new concepts waiting to keep the field from stagnating.

Be flexible. The NHGRI deserves credit for allowing Schloss to operate the programme differently from most of its schemes. For instance, reviewers were allowed to award small chunks of money to parts of an application that seemed promising, rather than cutting off funding for every project that failed to meet a milestone. This allowed the programme to provide more grants than would otherwise have been possible.

Of course, just incorporating these six elements into a programme does not guarantee success. Entrepreneurs and academic scientists have contributed ideas and drive to genomics advances, and venture capitalists have contributed money. And although the \$1,000 goal is within striking distance, it has not yet enabled the depth of understanding needed to make full medical or biological use of the knowledge derived from ever more genomes. Attacking that problem is the next challenge of genomics. But in part because of the $\$ 1,000$ genome programme, biologists are now in a position to address it.

\section{Past wisdom}

\section{The recent Nature PastCast series is instructive as well as entertaining.}

$F_{\mathrm{d}}^{\mathrm{o}}$ our decades ago, in August 1975, a short paper on antibodies was published in Nature. The findings spawned a multibillion-dollar drug industry: the monoclonal antibody drugs Herceptin, used to treat breast cancer, and Humira, used to treat rheumatoid arthritis, were together worth around US $\$ 15.4$ billion to the pharmaceutical industry in 2012. But the revolution was nearly stillborn: the published technique to make monoclonal antibodies could not be reproduced. The crisis was such, says historian Lara Marks at King's College London, that the authors considered withdrawing their article from Nature.

It was years before the investigations paid off and the huge medical potential of monoclonal antibodies started to crystallize. "Nowadays it seems prophetic," says Greg Winter, who made the first monoclonal antibody for use in humans. "But at that point I don't think anyone had realized the importance."

If those who do not learn from the past are truly doomed to repeat the same mistakes, then Nature has done its bit over the past few months to help them avoid that fate.

There are many lessons from history in our archive, alongside nuggets of scientific insight and experience. Some of these - and contemporary reflections on them from experts such as Marks - have been presented in the Nature PastCast, a 12-part audio series on the history of science that draws to a close this week. Some stories featured in the series are humbling; others simply entertaining. All are relevant.
Are you navigating a tricky international collaboration? So was astronomer Arthur Eddington, who tried to mount an expedition to view a solar eclipse as the First World War was drawing to a close. He was an Englishman - a pacifist Quaker to boot — trying to find evidence to support a German-born physicist's theory (Albert Einstein's general theory of relativity). Or maybe your desk is piled high with a backlog of data needing analysis? In the mid-1980s, climate scientist Jonathan Shanklin had to sift through reams of the stuff before the evidence for the ozone hole popped out at him.

Or are you having trouble avoiding jargon in your latest write-up? In a November 1919 discussion of relativity, the physicist J. J. Thomson is reported to have 'regretted the very complicated form in which Einstein expressed his theory, and hoped it might be possible to put it into a form in which it would be more generally comprehensible and useful'.

Some of the best stories are those that reflect a simple commitment to doing science. In November 1924, palaeontologist Raymond Dart was getting ready to appear as best man at his friend's wedding when a box of fossils arrived at his home in Johannesburg. Having an inkling of its content, he couldn't resist opening the package. In his diary, Dart recounts how the groom himself had to drag him away. "My God, Ray, you've got to finish dressing!"

Wilhelm Röntgen showed similar mettle. According to Otto Glasser's 1934 biography, in the days after he first discovered X-rays, Röntgen ate and slept in his lab "in order to avoid the distracting influence of daily trivialities, and to be able to continue his experiments immediately in case of a sudden inspiration". Once Röntgen had published his X-ray experiments, a journal- $\rightarrow$ NATURE.COM To comment online, click on Editorials at: go.nature.com/xhunqu ist asked him what he thought of his new findings. Röntgen gave a reply that every researcher should consider sticking on their fridge. "I did not think; I investigated." 